\title{
Evaluating wind technicians' performance on safety-critical rescue steps
}

\section{Kenneth Lawani PhD}

Lecturer in Construction Project Management, Department of Construction and Surveying, Glasgow Caledonian University, Glasgow, UK

(corresponding author: kenneth.lawani@gcu.ac.uk)

Billy Hare PhD

Deputy Director, Built Environment Asset Management Research Centre;

Professor, Construction Management, Glasgow Caledonian University,

Glasgow, UK

\section{Iain Cameron PhD}

Dean, School of Engineering and Built Environment, and Professor, Construction Safety and Health Management, Glasgow Caledonian University, Glasgow, UK

This paper reports the results of an analysis on the performance levels of wind technicians at 1 month and 3 months on safety-critical steps using situational judgement tests (SJTs) and job knowledge tests (JKTs) to assess their emergency rescue and evacuation proficiency. The research design is a repeat-measures study (longitudinal), using SJTs and JKTs to assess job-specific knowledge and job-related situations. It measured procedural knowledge in addition to aspects of declarative knowledge and fluid abilities, and this was considered as a good predictor of performance for wind technicians. The results indicate that rescue and evacuation skills decay within 1 month and 3 months after wind turbine rescue and evacuation training with 47 and $20 \%$ of technicians experiencing such decay in their skills and knowledge. These findings have practical implications for activities involving rescue and evacuation of workers - for example, crane driver rescue. The implementation of SJTs and JKTs indicates that skill decay takes place within the first 4 weeks after acquisition. Likewise, job knowledge is more resistant to decay compared with skill tasks over the 3 months' retention time frame for both refresher and new wind technicians.

\section{Introduction}

The retention of skills after episodes of non-use or non-practice has significant consequences when the learned skills are not applied over a long period of time after training. When skills and knowledge are not used over an extended period, they gradually deteriorate (Arthur et al., 2007, 2010, 2013; Kluge and Frank, 2014). This is particularly dangerous in situations where workers are initially trained on skills and knowledge that they may not have the opportunity to perform routinely. Lack of adequate evaluation of performance can potentially lead to accurate identification and prediction of skill decay. In the context of this paper, the term 'workers' refers to wind technicians involved in the construction and maintenance of wind turbines (returning or refresher technicians and new or first-time technicians).

The safe and competent use of constant-rate descenders (CRDs) requires specific operating skills. These wind turbine rescue and evacuation devices are commonly used for the rescue of oneself and casualties during accident or emergency situations while working in a wind turbine generator (WTG). Technicians tend to forget easily the procedural steps associated with these wind turbine rescue devices because multiple steps are required to deploy the devices successfully and the steps are not cued by preceding steps (Lawani, 2015). Correctly reacting to unusual rescue situations will require the technicians to have the requisite skills and detailed understanding of the operating theory of the rescue and evacuation device (Cesta et al., 2014; Reason, 2008). Most importantly, technicians require the skill- and knowledgebased rescue training to understand the functional requirements of the different rescue and evacuation devices, thus equipping them to deal with different emergency scenarios. This paper reports on the results of an analysis of a subset of data from a larger study on skill decay. It evaluates performance levels of wind technicians at 1 month and 3 months on some safety-critical steps by implementing 'situational judgement tests' (SJTs) and 'job knowledge tests' (JKTs) to assess their proficiency.

The Health and Safety at Work etc Act 1974, Provision and Use of Work Equipment Regulations 1998 (HMG, 1998) and Management of Health and Safety at Work Regulations 1999 (HMG, 1999) all require secured and effective emergency response to incidents/ accidents with the likelihood of affecting persons, and this study extends this relationship to onshore/offshore wind turbine installations. Equally, the initial response during emergency rescue and evacuation from a WTG is dependent on the competence and skill set of technicians that are involved.

Wind technicians undergo basic level height safety and rescue training endorsed by RenewableUK (RUK) and the Global Wind Organisation (GWO). The industry assumes that technicians should be able to retain their competence in a fluid work environment with up-to-date knowledge and skills over a 2-year period before embarking on prescribed refresher training. Although, workplace and refresher training programmes have both been identified as having significant roles in maintaining knowledge and skills, a common limitation is when such training fails to address the requisite skill. Therefore, this study adopts a quick and effective means of evaluating technicians' knowledge and skill. Regulations such as the Construction (Design and Management) Regulations 2015 (HMG, 2015) emphasise the 
significance of skill, knowledge, training, qualifications and experience, which are core to carrying out emergency rescue and evacuation efficiently. Also, the Personal Protective Equipment at Work Regulations 1992 (HMG, 1992) require that information, instruction and training must be provided to users and that the extent of these reflects the complex nature of the equipment involved. Such training and instructions will be particularly rigorous for items such as specialised personal protective equipment - for example, the emergency CRD.

\section{Skill and knowledge decay}

'Skill' is a term describing the sequences of learned actions that are entrenched in the context of other ongoing events. Skill acquisition has been described in terms of stage or phase designations defining different aspects of the learning process (see the publications of Anderson (1983), Adams (1987), Kluge et al. (2010) and Kim et al. (2013)), while skill retention signifies the ability to perform following a break from a learning period (Kim et al., 2007, 2013; Kluge et al., 2016; Richardson-Klavehn and Bjork, 1988). Therefore, evaluating the skill and knowledge performance of technicians on safety-critical rescue steps after a period of time could potentially reveal the true effectiveness of manipulations executed during acquisition. The process of evaluating such skill could be both quantitative and qualitative changes in behaviour. The quantitative changes come in the form of rapid anomalies in numerically measurable aspects of performance rate. A decay in the time taken by a technician to execute a particular rescue step as well as the number of errors committed while doing so are likely to be obvious, alongside increases in the amount of work completed within a given period (Annett, 1991; Kim et al., 2013; Kluge and Frank, 2014; Kluge et al., 2016). Qualitative changes could be associated with inconspicuous routines and habits of technicians and the absence of more obvious cues associated with the rescue kits.

\section{Rationale for SJT and JKT}

The SJT for this study was developed as a job test to reflect the realistic descriptions of rescue and evacuation procedures. SJTs assess individuals' reactions to a number of hypothetical rolerelevant scenarios, reflecting potential conditions that participants come across in their target role (Patterson et al., 2016). SJT is a measure of procedural knowledge in a specific domain. It is a measurement tool useful for evaluating job-related competencies and skills; and it is considered as a step detached from direct observation and built on the behavioural consistency logic (Lievens and De Soete, 2012; Lievens and Sackett, 2012; Lievens et al., 2008). This study therefore implemented SJT to appraise procedural knowledge and some aspects of declarative knowledge and fluid skills. This was considered as an auxiliary and valid evaluation of performance for wind technicians lacking the opportunity for routine hands-on practice after formal training. Furthermore, the SJT assessment for this study mimicked the realistic process of carrying out a rescue using visual twodimensional (2D) pictographs of the rescue device. The procedural steps were randomised in order to measure judgement skills directly related to the process of hands-on rescue (Motowidlo et al., 1990).

This study assumed that performances of wind technicians involved in the SJT assessment could identify elements of lack of retention in safety-critical steps related to emergency rescue and evacuation. Motowidlo et al. (1990) consider SJTs as low-fidelity imitations because they do not require participants to display actual behaviour but instead confront them with written descriptions of realistic job situations. Sackett et al. (2001) and Whetzel and McDaniel (2009) noted that most low-fidelity imitations (SJTs and JKTs) for assessing participants with practical experience could build more on participants' existing foundation of knowledge (Anderson et al., 2017).

JKT was useful in assessing technicians' declarative knowledge that is, knowledge of facts, rules and principles (Kanfer and Ackerman, 1989; McCloy et al., 1994; Patterson et al., 2016; Zierke, 2014). The JKT for this study required technicians to demonstrate their theoretical understanding and knowledge of working at height, rescue and evacuation as a good indicator for evaluating knowledge performance. The SJT and JKT assessments covered aspects such as

- dangers of working at height

- how to assess the hazards and implement effective controls

- how to use restraint, positioning and fall-arrest systems

- selecting proper anchor points

- practical climbing on ladders using fixed vertical safety systems

- recognising and dealing with suspension trauma

- planning for emergency procedures

- features and limitations of the rescue equipment being used

- how to rescue a suspended colleague from an in-reach or outof-reach situation.

$\mathrm{SJT} / \mathrm{JKT}$ was practical to administer to wind technicians, and the identification of the safety-critical task steps and the correct performance sequence of the CRD were mutually identified by the authors and an RUK-accredited specialist training company. The assessment was calibrated by adopting the cumulative sum approach (Bohm and Hackl, 1996) based on correct rescue and evacuation performance steps. Therefore, both SJT (procedural knowledge) and JKT (declarative knowledge) assessed jobspecific knowledge and measured various kinds of procedural knowledge such as critical decision-making situations.

\section{Reliability of SJT and JKT}

The research embarked on a pilot study with 15 wind technicians to refine and develop the research instruments explicitly (Gillham, 2000), assess degrees of observer bias (Hammersley and Atkinson, 1995; Hróbjartsson et al., 2013) and use the experience to review questions and adapt the study approach. The pilot study analysed the reliability of the instruments as part of the preliminary phase. The internal reliability using a Cronbach's 
alpha of $0 \cdot 810$ suggested very good internal consistency reliability for the scale (Pallant, 2011). This is within the range proposed by McDaniel et al. (2001). Therefore, this study implemented online assessment with the 2D pictographs of the rescue device for the SJT and JKT assessments.

\section{Wind technicians and type of training}

Basic height rescue and evacuation training is mandatory for wind technicians that access and work both onshore and offshore in a WTG during stages of construction, commissioning, operations and maintenance of wind turbines. Therefore, assessing the technician's capability to execute correctly and procedurally the acquired rescue skills after periods of non-practice is essential to avoid complications during times of emergency rescue. Participants for this study comprise 'returning' and 'first-time' wind technicians registered to undergo the $2 \mathrm{~d}$ mandatory RUKand GWO-approved work at height and rescue training (RenewableUK, 2014).

\section{Sources of data}

The data for this paper were collected by the researcher after undergoing training and mentoring with the RUK-approved height safety and rescue specialist training company.

\section{Description of applied research method}

This study initially recruited 82 wind technicians with varying years of on-the-job experience, skill, training and competence ( 0 to $\geq 10$ years), which are assumed to represent the wider population. The rationale for engaging these number of technicians was to accommodate dropout effects in longitudinal research (Creswell, 2014; de Vaus, 2001). Dropouts are often associated with longitudinal research most particularly when there are no incentives for participants to continue over a period of time as was the case for this study. Therefore, the longitudinal study focused on participants that took part in the whole assessment session. The wider study collected data before training (preacquisition), during training (acquisition), immediately after training (peak acquisition) and this paper focuses on the posttraining data (retention) at 1 - and 3 -month periods.

The rationale for adopting the time frames of 1 month and 3 months was based on research that non-routine complex procedural tasks are highly subject to forgetting after a relatively short period of non-practice (Wixted, 2004; Wixted and Ebbesen, 1991). Also, there are no standardised time frames set out for the evaluation of skill retention as observed in the works of Sauer et al. (2000), Arthur et al. (2002), Kim et al. (2007), Meador and Hill (2011) and Kluge and Frank (2014), which signifies that evaluations are established on individual capability. Similarly, based on the peripatetic nature of wind technicians and the prescribed refresher time frame of 2 years by RUK and GWO, this study objectively adopted an early refresher time frame of 1 month and 3 months, predicting that technicians would not have embarked on any rescue and evacuation training or practice drills after formal training. Therefore, 30 wind technicians fully participated in the skill and knowledge assessments from pre- to post-acquisition phases accounting for dropout effects.

The wind technicians were presented with a randomised procedure of how to use the rescue device for evacuation purposes. They were required to simulate procedurally the lifting and lowering of a casualty involved in an accident over a short distance by implementing the correct sequence. These procedural descriptions are requirements of the formal training that wind technicians will typically come across during rescue and evacuation of casualties involved in accidents within the WTG.

\section{Measures and data collection}

Retention measures were conducted online at 1 month and 3 months using structured JKTs and SJTs for knowledge and skill assessment, by adopting the approved tests by the regulating body. The SJT enabled wind technicians to recognise the specific rescue device (from a 2D pictograph), which is one of several rescue devices they get trained on. The SJT also helps the technicians to identify and simulate the correct procedural stepby-step method of using the rescue device, presented as a written description of a realistic rescue and evacuation operation.

The JKT covered aspects such as introduction to personal fall protection; general safety requirements for working in a WTG; procedures for access/egress and working within the turbine; selection, care and maintenance of equipment; restraint, work positioning and fall-arrest systems; principles of continuous attachments; types of anchorage in the WTG; and suspension syncope and emergencies based on the RUK-prescribed testing for technicians.

\section{Findings}

\subsection{SJT results}

The SJT assessment had ten procedural steps needed to carry out rescue. These steps were randomised at 1 month's and 3 months' retention assessments to evaluate if technicians could recall the sequence. Figure 1 shows the performance change at 1 month's and 3 months' retention measures. The study applied a limit state performance of $70 \%$ as a benchmark of good practice (Lawani et al., 2015). The result indicated that 14 wind technicians performed below this $70 \%$ benchmark at 1 month's and 3 months' retention, while 16 technicians performed at $\geq 70 \%$ benchmark.

Four technicians had performances of $<70 \%$ at 1 month's retention but showed improvements in their performance at 3 months' retention $(\geq 70 \%)$. These four technicians were identified as those that had undergone the refresher training, meaning they have previously been trained on the rescue device, which could probably be the precursor for the performance spike. Similarly, the 2D pictograph incorporated as part of the evaluation process could have positively triggered the returning technicians' recall of the implementation of the rescue device. Conversely, 


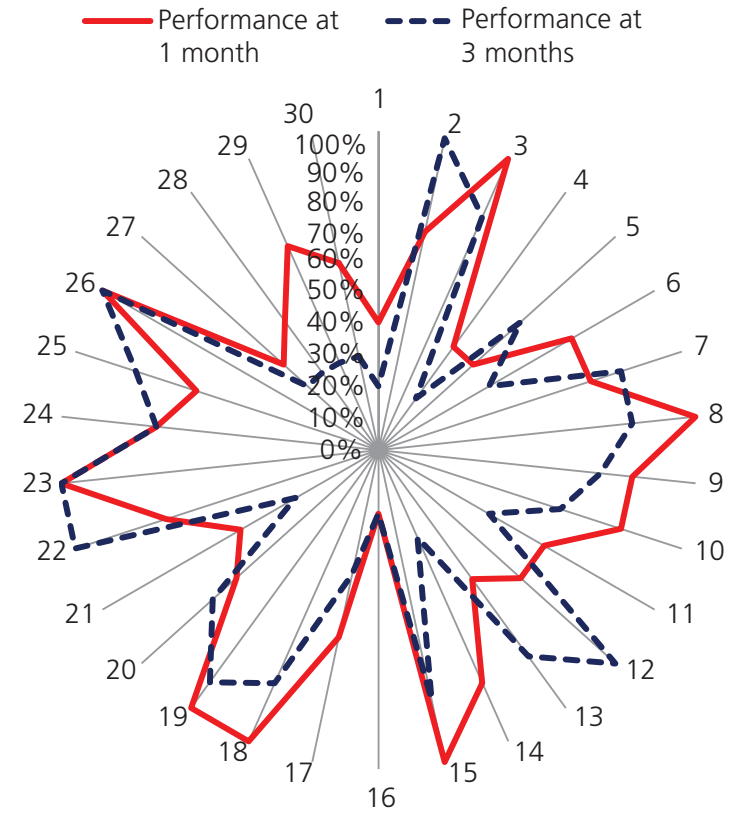

Figure 1. Percentage of skill performance using $70 \%$ as limit state measure for 30 technicians at 1 month's and 3 months' retention

four technicians had their performance dip from $\geq 70$ to $<70 \%$, and these were identified as new technicians that have undergone the rescue and evacuation training for the very first time. Their performance dip could be as a result of their lack of competence and non-practice with the rescue device. This indicates that skill decay is pervasive at 1 month and 3 months after the formal rescue and evacuation training with new technicians. It also indicates that the highest degree of skill decay is predominantly within the first 4 weeks after training and then thereafter.

The wind technicians were assessed on five safety-critical steps $(3,5,7,8$ and 9$)$ to determine their susceptibility to making errors and the tendency to complicate further the rescue process. These steps include attaching control rope to friction stud; locking off the CRD (brake) and turning the plunger on the side to prevent free fall; pushing the silver ball bearing button to close up the wheel; unlocking the CRD (brake) by off weighting the wheel and pulling out the plunger quarter turn; and finally folding the handle back into groove to prevent accident. The average performance from the data indicates that the technicians showed no improvement in their ability to execute successfully task steps 3, 5, 7, 8 and 9 at 1 month's and 3 months' retention intervals; see Table 1 and Figure 2. These five safety-critical steps are fundamental to the rescue process - that is, lifting and lowering a casualty from an in-reach and an out-of-reach environment.

Figure 2 shows the performance output and safety-critical steps that technicians displayed no improvement in. Fourteen technicians could not correctly execute task step 3 at 1 month and 3 months - that is, attaching the control rope to the friction stud.
Table 1. Technicians' error rates on safety-critical tasks at 1 month's and 3 months' retention tests

\begin{tabular}{|c|c|c|c|c|}
\hline \multirow{2}{*}{ Safety-critical skill steps } & \multicolumn{2}{|c|}{$\begin{array}{l}\text { Technicians } \\
\text { at } 1 \text { month's } \\
\text { retention }\end{array}$} & \multicolumn{2}{|c|}{$\begin{array}{l}\text { Technicians } \\
\text { at } 3 \text { months' } \\
\text { retention }\end{array}$} \\
\hline & $\begin{array}{l}\text { Tech. } \\
\text { right }\end{array}$ & $\begin{array}{l}\text { Tech. } \\
\text { wrong }\end{array}$ & $\begin{array}{l}\text { Tech. } \\
\text { right }\end{array}$ & $\begin{array}{l}\text { Tech. } \\
\text { wrong }\end{array}$ \\
\hline $\begin{array}{l}\text { Q3: attach the control rope to } \\
\text { the friction stud }\end{array}$ & 16 & 14 & 16 & 14 \\
\hline $\begin{array}{l}\text { Q5: lock off the CRD (brake) and } \\
\text { turn the plunger on the side to } \\
\text { prevent free fall }\end{array}$ & 23 & 7 & 17 & 13 \\
\hline $\begin{array}{l}\text { Q7: push the silver ball bearing } \\
\text { button to close up the wheel }\end{array}$ & 11 & 19 & 9 & 21 \\
\hline $\begin{array}{l}\text { Q8: unlock the CRD (brake) by off- } \\
\text { weighting the wheel and pulling } \\
\text { out the plunger quarter turn }\end{array}$ & 11 & 19 & 11 & 19 \\
\hline $\begin{array}{l}\text { Q9: fold the handle back into } \\
\text { groove }\end{array}$ & 8 & 22 & 6 & 24 \\
\hline
\end{tabular}

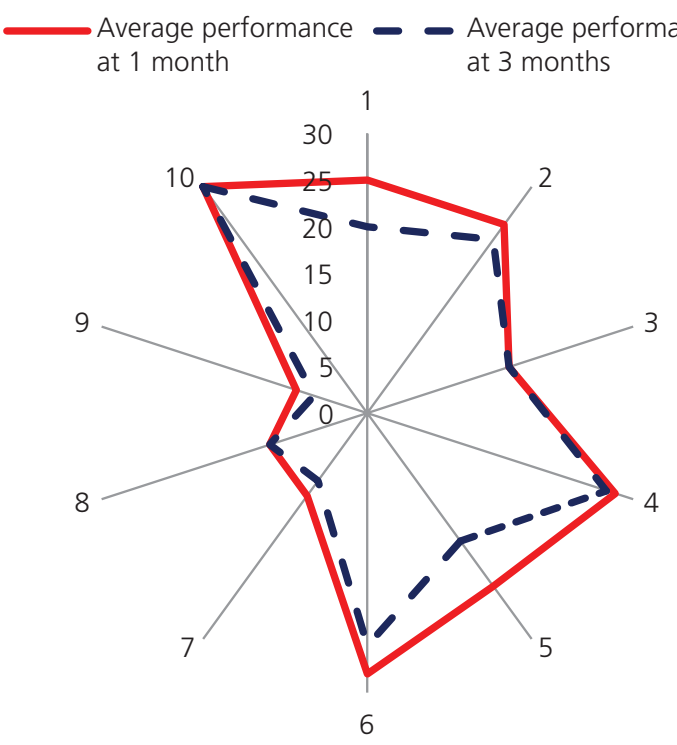

Figure 2. Performance output per skill step at 1 month and 3 months for 30 technicians

Seven and 13 technicians could not correctly execute task step 5 at 1 month and 3 months - that is, locking the device by using the plunger on the side of the device to prevent the free fall of the casualty. Nineteen and 21 technicians could not successfully execute task step 7 at 1 month and 3 months - that is, closing up the device wheel by using the silver ball bearing. Nineteen technicians could not execute task step 8 at 1 month and 3 months - that is, unlocking the brake system of the CRD by off-weighting the wheel and pulling out the plunger quarter turn. Twenty-two and 24 technicians could not successfully execute task step 9 at 1 month and 3 months - that is, folding the handle back into the groove to prevent accidental contact with the rescuer and casualty - and this could further lead to a more complicated 
rescue scenario. The technicians consistently showed no improvement in their performance on these five safety-critical steps, which are considered fundamental to a successful execution of rescue and evacuation of a casualty using the device.

These safety-critical steps make up part of the procedural process not cued by the device and when forgotten could further complicate the rescue process and the safety of the casualty and the rescuer. These further confirm that some safety-critical steps regarding the use of the rescue device are amenable to the impact of skill decay at 1 month's and 3 months' retention intervals. This indicates that with the passage of time, there is a pattern of decay regarding the correct implementation and sequencing of rescue and evacuation by wind technicians in the absence of hands-on practice.

\subsection{JKT results}

The design of the JKT assessment had 15 knowledge questions for assessing technicians' declarative knowledge of rescue and evacuation. These questions were randomised at retention intervals of 1 month and 3 months to evaluate if technicians could recall the correct answers. The $70 \%$ limit state performance was also implemented, and Figure 3 shows performance scores at 1 month's and 3 months' retention for 30 wind technicians. It identifies that 24 wind technicians performed above $\geq 70 \%$, while six were below the specified limit state. The performances in the JKT assessment also indicate some convergence in the scores over this time frame. Three technicians performed below the $70 \%$ limit state at 1 month's retention and above $70 \%$ at the 3 months' retention assessment. These were technicians that had undergone the refresher training exercise. Similarly, three technicians that

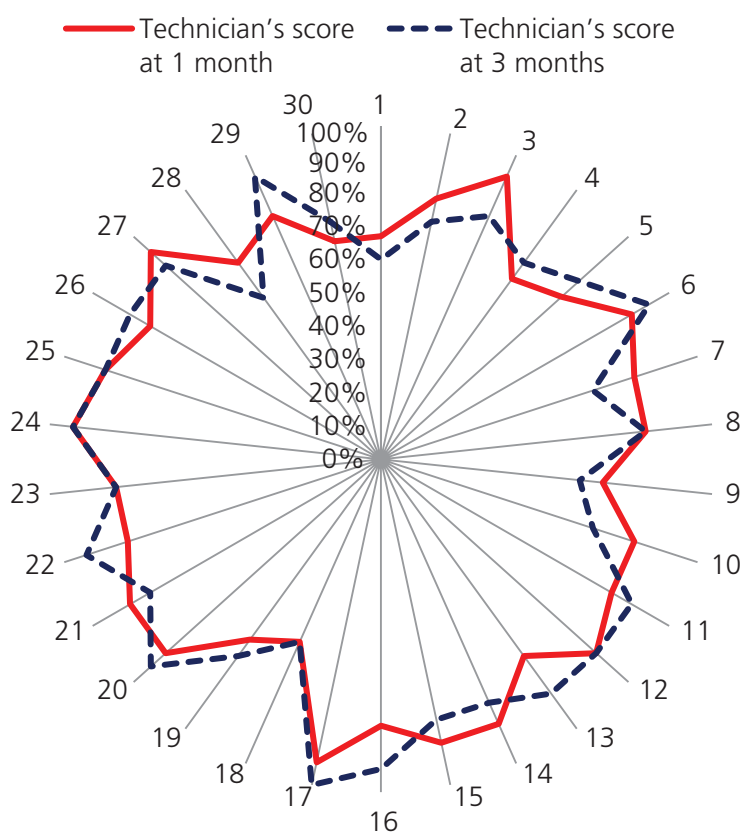

Figure 3. Percentage knowledge performance score and 70\% limit state for 30 technicians at 1 month's and 3 months' retention performed above the $70 \%$ limit state in the 1 month's retention test performed below the $70 \%$ limit state at 3 months' retention, and these were identified as technicians that had undergone the training for the very first time. Overall, this study identified a pattern and consistency of performance regarding the JKT test, which reveals higher retention compared with skill performance at 1 month's and 3 months' retention.

Figure 4 shows the output from the 15 questions used for the 1 month's and 3 months' JKT retention assessment, while Table 2 shows the number of technicians that accurately provided the right answers to the safety-critical knowledge questions (i.e. questions 4, 7, 9, 11 and 12) and technicians that got it wrong.

The JKT assessment on the five safety-critical knowledge questions reveal that Q7, Q9 and Q12 showed some increment in the number of technicians that got the questions wrong over the 1 month's and 3 months' retention intervals, while the number of participants that got Q4 and Q11 wrong declined.

\section{Discussions, practical implications and conclusions}

The SJT results show 16 technicians with performances $\geq 70 \%$ and 14 technicians with performances $\leq 70 \%$ at 1 month's and 3 months' retention. This indicates that some technicians (typically new or first-time) will struggle to sustain their competency after 3 months if they are not exposed to some forms of practice after initial rescue and evacuation training. It indicates that the lack of non-routine practice by technicians could lead to skill decay, and this study proposes a mandatory refresher practice drill to sustain technicians' competency. Evidence suggests that for a successful transfer of training and for skills to

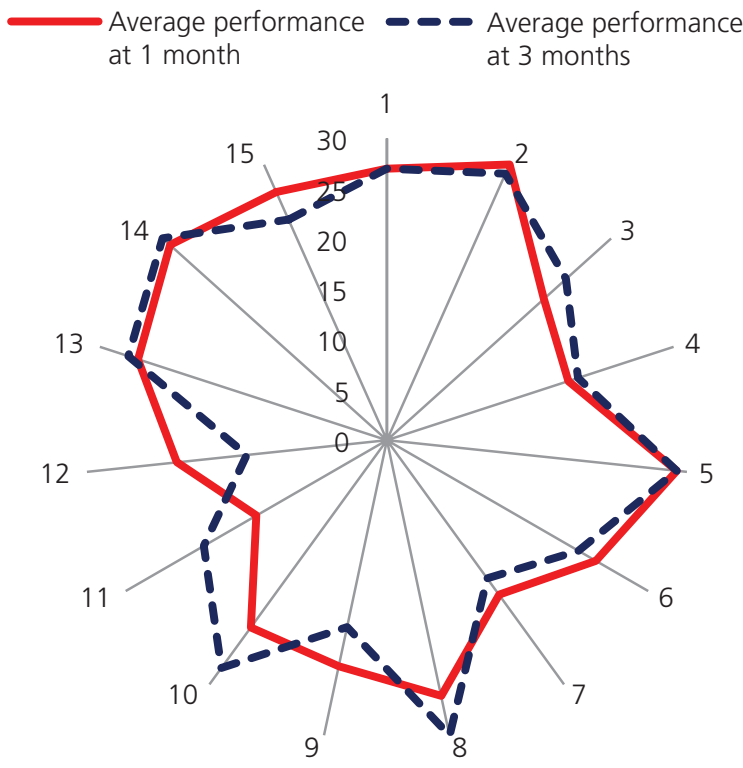

Figure 4. Performance output per knowledge questions at 1 month and 3 months for 30 technicians 
Table 2. Technicians' error rates on safety-critical questions at 1 month's and 3 months' retention tests

\begin{tabular}{|c|c|c|c|c|}
\hline \multirow{2}{*}{$\begin{array}{l}\text { Safety-critical knowledge } \\
\text { questions }\end{array}$} & \multicolumn{2}{|c|}{$\begin{array}{l}\text { Technicians } \\
\text { at } 1 \text { month's } \\
\text { retention }\end{array}$} & \multicolumn{2}{|c|}{$\begin{array}{l}\text { Technicians } \\
\text { at } 3 \text { months' } \\
\text { retention }\end{array}$} \\
\hline & $\begin{array}{l}\text { Tech. } \\
\text { right }\end{array}$ & $\begin{array}{l}\text { Tech. } \\
\text { wrong }\end{array}$ & $\begin{array}{l}\text { Tech. } \\
\text { right }\end{array}$ & $\begin{array}{l}\text { Tech. } \\
\text { wrong }\end{array}$ \\
\hline $\begin{array}{l}\text { Q4. Which one of the following } \\
\text { gives the greatest protection } \\
\text { when working at height? }\end{array}$ & 19 & 11 & 20 & 10 \\
\hline $\begin{array}{l}\text { Q7. What should never be done } \\
\text { with a fixed vertical safety } \\
\text { system, e.g. a wire slider? }\end{array}$ & 19 & 11 & 17 & 13 \\
\hline $\begin{array}{l}\text { Q9. What is the recommended } \\
\text { clearance required for effective } \\
\text { use of a fall-arrest system } \\
\text { containing a } 2 \text { m energy } \\
\text { absorbing lanyard? }\end{array}$ & 23 & 7 & 19 & 11 \\
\hline $\begin{array}{l}\text { Q11. How often should product } \\
\text { being used for regular work } \\
\text { positioning be subject to } \\
\text { examination? }\end{array}$ & 15 & 15 & 21 & 9 \\
\hline $\begin{array}{l}\text { Q12. What is the recommended } \\
\text { typical life time of a textile } \\
\text { product which has sustained } \\
\text { regular use? }\end{array}$ & 21 & 9 & 14 & 16 \\
\hline
\end{tabular}

be retained over a period of time, it is fundamental that the resources and available opportunities to practice and perform the newly acquired skills are present (Burke and Hutchins, 2007; Clarke, 2002; Salas et al., 2006; Weissbein et al., 2010).

Previous studies have emphasised that in many domains, expert performances are displayed by individuals having more than 10 years of experience; see the publication of Patel and Groen (1991). However, Ericsson et al. (1993) were keen to point out that a sufficient amount of experience or practice does not amount to maximal performance as previously believed. This paper identifies that both new and returning technicians with diverse experiences attained variable performance scores in the SJT and JKT assessments. Therefore, SJT and JKT have the capacity to improve the performances of highly experienced and skilled but individually different wind technicians when they embark on an abridged deliberate and routine forms of practice of rescue and evacuation procedures no more than 3 months after initial training (Ackerman, 2013).

The results from JKT assessment show that 24 wind technicians had average performance scores $\geq 70 \%$, while six technicians had performance scores $<70 \%$ at 1 month and 3 months. This result further reaffirms that the retention of knowledge can be sustained longer than skills. It also identifies that wind technicians are capable of maintaining their knowledge base up to 3 months (Lawani et al., 2015). A point of caution, however, is that too much reliance on high performance scores from knowledge assessment will lead to a false sense of security in terms of the overall procedural competence of the wind technicians.
Previous studies have implemented different time intervals in evaluating skill and knowledge retention - for example, from $1 \mathrm{~d}$ to as long as 2 years (Kim et al., 2013; Marmie and Healy, 1994; Oermann et al., 2011; Wisher et al., 1991). The result from this study regarding skill and knowledge decay at 1 month and 3 months aligns with studies carried out by Marmie and Healy (1994), which recorded a statistically significant decay in the retention rate in the 1 month's and 6 months' retention assessments, and Oermann et al. (2011), which showed that cardiopulmonary resuscitation (CPR) skills continued to improve or were maintained with deliberate monthly practice of only $6 \mathrm{~min} / \mathrm{month}$. Implementing SJT and JKT forms of evaluation as a low-fidelity and a deliberate practice intervention can potentially improve the performance of technicians on safety-critical rescue steps before they embark on any form of hands-on refresher training (Kessler $e t$ al., 2011; Maagaard et al., 2011).

The five safety-critical steps (Table 1) identified in the SJT assessment based on the rescue and evacuation device are uncued and lack a logical procedure, and these steps tend to be the least likely recalled (Lawani, 2015; Lawani et al., 2015). This study identified that the technicians showed no performance improvement on uncued safety-critical skill steps at 1 month's and 3 months' retention after initial training. Therefore, the device reported in this paper falls short of logical, procedural task steps, which could be one of the contributory reasons why technicians tend to forget easily these safety-critical steps inherent to the device.

Findings from this paper, which are based on primary data, suggest variable rates for skill and knowledge retention at 1 month and 3 months. It can be inferred that the degree of successful performance of technicians on these assessments is largely dependent on their aptitude, learning and training and experience or the type of practice and instructions previously received. To attain consistency in rescue and evacuation skills, there should be sustained and deliberate practice of such skills that is bespoke.

Safe rescue and evacuation from a wind turbine requires robust procedures to be firmly in place, and this study recommends that employers should intermittently evaluate the technicians' training, skills and competence to minimise the effect of skill decay. Likewise, future designs of rescue and evacuation devices should incorporate fewer task steps as this could likely improve retention. Other allied industries such as telecommunications, industrial climbing and rigging, scaffolding and tower crane using rescue devices are also prone to similar retention of rescue skills. This paper concludes that implementing SJT and JKT assessments as an evaluation tool can provide useful information relevant to skill and knowledge retention and can be used for strategic refresher training purposes.

\section{Lessons for worker safety in the broader construction industry and implications for international industry practices}

The result from this study suggests that first-time technicians involved in rescue and evacuation training but without the 
opportunity for routine practice could potentially be vulnerable to accidents even after initial training - that is, quicker skill decay. This could be curtailed through timely evaluation of their performance on some safety-critical rescue steps and selective retraining and mentoring opportunities in order to improve their competency.

This study can potentially inform rescue and evacuation device manufacturers in minimising complex deployment steps and introducing cues and error-correction strategies and simplified instructions in the deployment of rescue kits. The wider impact of this research is the ability to replicate the SJT and JKT forms of assessment in other height rescue kits used for emergency rescue and evacuation of workers.

\section{REFERENCES}

Ackerman PL (2013) Nonsense, common sense, and science of expert performance: talent and individual differences. Intelligence 45: 6-17, https://doi.org/10.1016/j.intell.2013.04.009.

Adams JA (1987) Historical review and appraisal of research on the learning, retention, and transfer of human motor skills. Psychological Bulletin 101(1): 41-74, https://doi.org/10.1037/0033-2909.101.1.41.

Anderson JR (1983) The Architecture of Cognition. Harvard University Press, Cambridge, MA, USA.

Anderson G, Hughes C, Patterson D and Costa J (2017) Enhancing interprofessional education through low-fidelity simulation. British Journal of Midwifery 25(1): 52-58, https://doi.org/10.12968/bjom.2017.25.1.52.

Annett J (1991) Skill acquisition. In Training for Performance: Principles of Applied Human Learning (Morrison JE (ed.)). Wiley, Chichester, UK, pp. 13-51.

Arthur W Jr, Benneth W Jr, Day EA and McNelly TL (2002) Skill Decay: a Comparative Assessment of Training Protocols and Individual Differences in the Loss and Reacquisition of Complex Skills. US Air Force Research Laboratory, Mesa, AZ, USA, AFRL-HE-AZ-TR-20020004.

Arthur W Jr, Day EA, Villado AJ et al. (2007) Decay, Transfer, and Reacquisition of a Complex Skill: an Investigation of Practice Schedules, Observational Rehearsal, and Individual Differences. Aptima, Woburn, MA, USA.

Arthur W Jr, Day EA, Villado AJ et al. (2010) The effect of distributed practice on immediate posttraining, and long-term performance on a complex command-and-control simulation task. Human Performance 23(25): 428-445, https://doi.org/10.1080/08959285.2010.515277.

Arthur W Jr, Day A, Bennett W Jr and Portrey AM (2013) Individual and Team Skill Decay: the Science and Implications for Practice. Routledge, New York, NY, USA.

Bohm W and Hackl P (1996) The effect of serial correlation on the incontrol average run length of cumulative score charts. Journal of Statistical Planning and Inference 54(1): 15-30, https://doi.org/10. 1016/0378-3758(95)00153-0.

Burke LA and Hutchins HM (2007) Training transfer: an integrative literature review. Human Resource Development Review 6(3): 263-296.

Cesta A, Cortellessa G and De Benedictis R (2014) Training for crisis decision making - an approach based on plan adaptation. Knowledge-based Systems 58: 98-112, https://doi.org/10.1016/j.knosys.2013.11.011.

Clarke N (2002) Job/work environment factors influencing training effectiveness within a human service agency: some indicative support for Baldwin and Fords' transfer climate construct. International Journal of Training and Development 6(3): 146-162, https://doi.org/ 10.1111/1468-2419.00156.

Creswell JW (2014) Research Design: Qualitative, Quantitative, and Mixed Methods Approaches, 4th edn. Sage, Thousand Oaks, CA, USA. de Vaus DA (2001) Research Design in Social Research. Sage, London, UK.

Ericsson AK, Krampe RT and Tesch-Romer C (1993) The role of deliberate practice in the acquisition of expert performance. Psychological Review 100(3): 363-406, https://doi.org/10.1037//0033-295X.100.3. 363.

Gillham B (2000) Case Study Research Methods. Continuum, London, UK.

Hammersley M and Atkinson P (1995) Ethnography: Principles in Practice. Routledge, London, UK.

Health and Safety at Work etc Act 1974. Chapter 37. Her Majesty's Stationery Office, London, UK.

HMG (Her Majesty's Government) (1992) Personal Protective Equipment at Work Regulations 1992. The Stationery Office, London, UK, Statutory Instrument 1992 No. 2966.

HMG (1998) Provision and Use of Work Equipment Regulations 1998. The Stationery Office, London, UK, Statutory Instrument 1998 No. 2306.

HMG (1999) Management of Health and Safety at Work Regulations 1999. The Stationery Office, London, UK, Statutory Instrument 1999 No. 3242.

HMG (2015) Construction (Design and Management) Regulations 2015. The Stationery Office, London, UK, Statutory Instrument 2015 No. 51.

Hróbjartsson A, Thomsen ASS, Emanuelsson F et al. (2013) Observer bias in randomized clinical trials with both blinded and nonblinded assessors. Canadian Medical Association Journal 185(4): E201-E211, https://doi.org/10.1503/cmaj.120744.

Kanfer R and Ackerman PL (1989) Motivation and cognitive abilities: an integrative/aptitude-treatment interaction approach to skill acquisition. Journal of Applied Psychology 74(4): 657-690, http://dx.doi.org/10. 1037/0021-9010.74.4.657.

Kessler DO, Auerbach M, Pusic M, Tunik MG and Foltin JC (2011) A randomized trial of simulation-based deliberate practice for infant lumbar puncture skills. Simulation in Healthcare 6(4): 197-203, https://doi.org/10.1097/SIH.0b013e318216bfc1.

Kim JW, Koubek RJ and Ritter FE (2007) Investigation of procedural skills degradation from different modalities. In Proceedings of the 8th International Conference on Cognitive Modeling. Taylor \& Francis/ Psychology Press, Abingdon, UK, pp. 255-260.

Kim JW, Ritter FE and Koubek RJ (2013) An integrated theory of skill acquisition and retention in the three stages of learning. Theoretical Issues in Ergonomics Science 14(1): 22-37, https://doi.org/10.1080/ 1464536X.2011.573008.

Kluge A and Frank B (2014) Counteracting skill decay: four refresher interventions and their effect on skill and knowledge retention in a simulated process control task. Journal of Ergonomics 57(2): 175-190, https://doi.org/10.1080/00140139.2013.869357.

Kluge A, Sauer J, Burkolter D and Ritzmann S (2010) Designing training for temporal and adaptive transfer: a comparative evaluation of three training methods for process control tasks. Journal of Educational Computing Research 43(3): 327-353, https://doi.org/10.2190/EC.43.3.d.

Kluge A, Frank B, Maafi S and Kuzmanovska A (2016) Does skill retention benefit from retentivity and symbolic rehearsal? - two studies with a simulated process control task. Ergonomics 59(5): 641-656, https://doi.org/10.1080/00140139.2015.1101167.

Lawani O (2015) Investigating Skill Decay of Wind Turbine Technicians in Emergency Rescues. PhD thesis, Glasgow Caledonian University, Glasgow, UK.

Lawani K, Hare B and Cameron I (2015) Scheduling refresher-based rescue and evacuation training for wind turbine technicians. In The Canadian Society for Civil Engineering 5th International/11th Construction Specialty Conference (Froese TM, Newton L, Sadeghpour F and Vanier DJ (eds)). The University of British Columbia, Vancouver, BC, Canada, pp. 95-1-95-10. 
Lievens F and De Soete B (2012) Simulations. In Handbook of Assessment and Selection (Schmitt N (ed.)). Oxford University Press, Oxford, UK, pp. 383-410.

Lievens F and Sackett PR (2012) The validity of interpersonal skills assessment via situational judgment tests for predicting academic success and job performance. Journal of Applied Psychology 97(2): $460-468$.

Lievens F, Peeters H and Schollaert E (2008) Situational judgment tests: a review of recent research. Personnel Review 37(4): 426-441, http://dx. doi.org/10.1108/00483480810877598.

Maagaard M, Sorensen JL, Oestergaard J et al. (2011) Retention of laparoscopic procedural skills acquired on a virtual-reality surgical trainer. Surgical Endoscopy 25(3): 722-727, https://doi.org/10.1007/ s00464-010-1233-5.

Marmie WR and Healy AF (1994) The long-term retention of a complex skill. In Learning and Memory of Knowledge and Skills: Durability and Specificity (Healy F and Bourne E Jr (eds)). Sage, Thousand Oaks, CA, USA, pp. 30-65.

McCloy RA, Campbell JP and Cudeck R (1994) A confirmatory test of a model of performance determinants. Journal of Applied Psychology 79(4): 493-505.

McDaniel MA, Morgeson FP, Finnegan EB, Campion MA and Braverman EP (2001) Use of situational judgment tests to predict job performance: a clarification of the literature. Journal of Applied Psychology 86(4): 730-740.

Meador DP and Hill RR (2011) Modeling training effects using a human performance taxonomy. Human Factors 53(4): 391-402, https://doi. org/10.1177/0018720811413766.

Motowidlo J, Dunnette MD and Carter GW (1990) An alternative selection procedure: the low-fidelity simulation. Journal of Applied Psychology 75(6): 640-647.

Oermann MH, Kardong-Edgren SE and Odom-Maryon T (2011) Effects of monthly practice on nursing students' CPR psychomotor skill performance. Resuscitation 82(4): 447-453, https://doi.org/10.1016/j. resuscitation.2010.11.022.

Pallant J (2011) SPSS Survival Manual: a Step by Step Guide to Data Analysis Using SPSS, 4th edn. Allen \& Unwin, Crows Nest, Australia

Patel VL and Groen GJ (1991) The general and specific nature of medical expertise: a critical look. In Toward a General Theory of Expertise
(Ericsson KA and Smith J (eds)). Cambridge University Press, Cambridge, UK, pp. 93-125.

Patterson F, Zibarras L and Ashworth V (2016) Situational judgement tests in medical education and training: research, theory and practice: AMEE Guide No. 100. Medical Teacher 38(1): 3-17, https://doi.org/ 10.3109/0142159X.2015.1072619.

Reason J (2008) The Human Contribution: Unsafe Acts, Accidents and Heroic Recoveries, 1 st edn. CRC Press, London, UK.

RenewableUK (2014) Working at Height \& Rescue Training Standard. RenewableUK and Global Wind Organisation, London, UK.

Richardson-Klavehn A and Bjork RA (1988) Measures of memory. Annual Review of Psychology 39: 475-543.

Sackett PR, Schmitt N, Ellingson JE and Kabin MB (2001) High-stakes testing in employment, credentialing, and higher education: prospects in a post-affirmative action world. American Psychologist 56(4): 302-318.

Salas E, Wilson K, Priest H and Guthrie J (2006) Design, delivery, and evaluation of training systems. In Handbook of Human Factors and Ergonomics (Salvendy G (ed.)), 3rd edn. Wiley, Hoboken, NJ, USA, pp. 472-512.

Sauer J, Hockey GRJ and Wastell DG (2000) Effects of training on shortand long-term skill retention in a complex multiple-task environment. Ergonomics 43(12): 2043-2064.

Weissbein DA, Huang JL, Ford JK and Schmidt AM (2010) Influencing learning states to enhance trainee motivation and improve training transfer. Journal of Business and Psychology 26(4): 423-435.

Whetzel DL and McDaniel MA (2009) Situational judgment tests: an overview of current research. Human Resource Management Review 19(3): 188-202

Wisher RA, Sabol MA, Sukenik HK and Kern RP (1991) Individual Ready Reserve (IRR) Call-up: Skill Decay. US Army Research Institute for the Behavioural and Social Sciences, Arlington, VA, USA.

Wixted JT (2004) On common ground: Jost's 1897 law of forgetting Ribot's 1881 law of retrograde amnesia. Psychological Review 111(4): 864-879.

Wixted JT and Ebbesen EB (1991) On the form of forgetting. Psychological Science 2(6): 409-415.

Zierke O (2014) Predictive validity of knowledge tests for pilot training outcome. Aviation Psychology and Applied Human Factors 4(2): 98-105.

\section{How can you contribute?}

To discuss this paper, please email up to 500 words to the editor at journals@ice.org.uk. Your contribution will be forwarded to the author(s) for a reply and, if considered appropriate by the editorial board, it will be published as discussion in a future issue of the journal.

Proceedings journals rely entirely on contributions from the civil engineering profession (and allied disciplines). Information about how to submit your paper online is available at www.icevirtuallibrary.com/page/authors, where you will also find detailed author guidelines. 